would be discovered between diarrhoea and carelessneos with regard to disposal of excreta and protection of fool from the visitation of tlies than between diarrhoea and fly prevalence.

Many of the facts which $I$ have brought forward merely indicate some form of infective agent, and do not necessitate recourse to the hypothesis that carriage by flies dominates the situation. I would, however, point out: (1) that the fly-carrier hypothesis is the only one which offers a satisfactory interpretation of the extraordinary dependence of the epidemic upon the accumulated effect of temperature; (2) that it offers a ready explanation of the spread of infection to neighbouring children who have no direct personal contact with the patient; (3) that the peculiarities of the relation in time between fly prevalence and the epidenic in different localities are not inconsistent with the view that fly carriage is essential to epidemicity.

No other interpretation which is, so far, forthcoming is nearly so satisfactory, and it is at least worthy to guide in the meantime our efforts at prevention.

Bibliography.-Ainsworth (1909) : The House Fly as a Disease Carrier, Journal of the Royal Army Medical Corps, vol. xii., p. 485. Aldridge (1908): House Flies as Carriers of Typhoid Infection, Journal of Tropical Medicine, vol. xi., p. 303 ; Journal of the Royal Army Medical Corps, vol. x., p. 135. Alessi (1888): Archivio per le Scienze Mediche,
vol. xil., p. 279. Axenfeld (1907): Die Bakteriologie in der Augen-
heilkundle. Jena, 1907. Bacot (1911): The Persistence of B. Pyocyaneus in Pupæ and Imagines of Musca Domestica, Parasitology, vol. iv., p. 67. Ballard (1889): Diarrhoea and Diphtheria, Supplement to Report of Medical Officer Local Government Board, 1887. Bertarelli (1910): Verbreitung des Typhus durch die Fliegen, Centralblatt fur Bakteriologie, I. Orig., Band liii., p. 486. Buchanan (1907) : Carriage of Observations on the Occurrence of Malignant Pustule in England, THE Laxcer, vol ii., p. 164. 1862. Cao, G. (1906) : Sul Passagio dei Germi a traverso le Larre di alcuni Insetti, Annali d'Igiene Sperimentale, rol. xvi., p. 645. Castellani (1907): Experimental Investigations on Frambosia Tropica (Yaws), Journal of Hygiene, vol. vii., p. 568. Celli (1888): Transmissibilita dei Germi Patogeni mediante le di Roma, fasc i p 1. Chantemesse (1905) Lancisiana degli Ospedali of Meeting Record, vol. lxviii., p. 989. Cobb (1905): Is the Common House Fly a Factor in the Spread of Tuberculosis? American Medicine, rol. ix., p. 475. Cochrane (1912): A Small Epidemic of Typhoid Fever in Connexion with specifically Infected Flies, Journal of the Royal in Connexion with Specifically Infected Flies, Journal of the Royal Army Medical Corps, vol. xviii., p. 271. Cordes (1903): Returbance in Infants, Proceedings of New York Pathological turbance in Infants, Proceedings of New York Pathological
Society, vol. iii., p. 147. Dudfield (1912): Diarrhoea in 1911, Proceedings of the Royal Society of Medicine, rol. v., Epidemiological Section, p. 99 . Duval and Schorer $(1903)$ : Results of the Examination of 79 Cases of Summer Diarrhoea, Proceedings of the New York Patbological Society, vol. iii., p. 144. Faichnie (1969): Fly-borne Enteric Fever and Source of Infection, Journal of the Royal Army Medical Corps, vol. xiii., p. 580. Ficker (1903): Typhus und Fliegen, Archiv into the Influence of Soil, \& in Dissemination of Fnteric Infection, into the Influence of Soil, \&c., in Dissemination of Enteric Infection,
Brit. Med. Jour., vol. ii., p. 936 . Galli-Va!erio (1910) : Ktat actuel de nos Connaissances sur le Rôle des Mouches dans la Dissémination des nos Connaissances sur le Role des Mouches dans la Dissémination des Maladies Parasitaires, \&c., Centralblatt fuir Bakteriologie, Orig., Band IV., p. 193. Graham-Smith (1910): Observations on the Ways, \&c., Flies Carry and Distribute Pathogenic Bacteria, Locsl Government Board Reports, New Series, No. 40. Graham-Smith (1911): Some Observations, \&c, on the Blow-Fiy, Journal of Hygiene, 1911, vol, xi,, p. 390 .
Graham-Smith (1911): Further Observations on the Ways in which Graham-Smith (1911): Further Observations on the Wajs in which Artificially Infected Flies Carry and Distribute Pathogenic and Other Medical Subjects, No. 53. Grassi (1883): Gazzetta degli Ospedali, No. 59, 1883 (quoted by Galli-Valerio 1910). Griffith (1908): LifeHistory of House Flies, Public Health Reports, p. 122. Hamer (1908, 1909, and 1910): Nuisance from Flies, Reports of the Public Health Committee of the London County Council, 1908, 1909, and 1910, Appendices. Hamilton (1903): The Fly as a Carrier of Typhoid, \&c,, Journal of American Medical Association, vol. ii. Hayward (1904) : The Fly as a Carrier of Tuberculosis Infection, New York Medical Journal, vol. 1xxx., p. 643. Hewitt (1907): Structure, Development, and Bionomics of the House Fly, Quarterly Journal of Medical Science, vol. li., part 3. Hewitt (1910): The House Fly, a Study of its Structure, \&c.. Manchester, the University Press. Hofmann (18< 8): Ueber die Verbreitung der Tuberkulose durch Stubenfliegen, Corresi ondenzblatt aerztl. Kreis. und Bezirksver. in Kónigreich Sachsen, Band xliv , p. 130. Howard (1912): The House Fly, Disease Carrier, London, John Murray 1912. Howe (1888): Egyptian Ophthalmia, Seventh Internationa (1906): The Spread of Plague Infen, Becker ansects, Centralblatt fï Bakteriologie, Oríg., Band xl., p. 43. Jehle and Charle ton (1905): Ueber Epidemische und Sporadische Ruhr im Kindesalter, Zeitschrift fur Heilkunde, Abt. Int. Med., Band xxvi., p. 402. Klinger (1909): Epidemiologische Beobachtungen bei der Typhusbekampfung in Sunesten des Reiches, Arbeiten aus nem Kaiserichen Gesind eits Bouton de Biskra. Annales Dermatologiques, 2 S., vol. i., p. 173. Ledingham (1911): On the Survival of Specific Micro-organisms in Pupx and Imagines of Musca Domestica, \&c., Journal of Hygiene, vol. xi., p. 333. Lord (1904): Flies and Tuberculosis, Boston Menical ac., of the Blow-Fly, London, R. H, Porter, 18. Princes-street, Cavendish-square. Lumsden and Anderson (1911): Report No. 4 on the Origin and Prevalence of Typhoid Fever in the District of Columbia, Bulletin No. 78, Hygiene Laboratory, United States Public (1885): Experiments on Feeding Insects with Comma Bacillus, \&c.,
Journal of the Royal Microscopical Society, Series 2, vol. v., p. 602 and p. 941. Manning (1902): A Preliminary Report on Transmission of Pathogenic Germs by the Common House Fly, Journal of the American Medical Association, vol. xxxviii., p. 1291. Metch-
nikoff (1909): Semaine Médicale, p. 361, 1969. Morgan (1966): Bacteriology : semaine Médicale, p. 361, 1969. Morgan (1966): Bacteriology of Summer Diarrhœea in Infants, Brit. Med. Jour,
April 21st, 19C6, vol. i., p. 908 . Morgan (1907) : Loc. cit., vol. ii., 1907, April 21st, 19C6, vol. i., p. 908. Morgan (1907): Loc. cit., vol. ii., 1907,
p. 16. Morgan and Ledingham (1909): Bacteriology of Summer p. 16. Morgan and Ledingham (1909): Bacteriology of Summer Section, March, 1909. Nash (1909): House Flies as Carriers of Disease Journal of Hygiene, vol. ix, p. 135. Newstead (1907) : Preliminary Report, \&c., of the Common House Fly as Observed in the City of Liverpool, Liverpool, C. Tinling and Co., Limited. Newstead (19C9): Second Interim Report. Nicoll (1911): Part Played by Flies in the Dispersal of the Eggs of Parasitic Worms, Reports to Local Government
Board on Public Health and Medical Subjects, New Series, No. 5, 1911. Board on Public Health and Medical Subjects, New Series, No. 5, 1911. Niven (1906) : Annual Report of Medical Officer of Health for
Manchester, p. 262. Niven (1910): House Fly in Relation to Summer Manchester, p. 262. Niven (1910): House Fly in Relation to Summer Diarrhcea and Enteric Fever, Proceedings of the Royal Society of Medicine, April, 1910, vol. iii. Nuttall, G. H. F. (1897): Zur

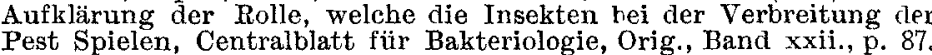
Park, Collins, and Goodwin (1903) : Results of an Investigation upon the Etiology of Dysentery and Acute Diarrhoea, Proceedings of New York Pathological Society, New Series, vol. ili., p. 148. Peters (1909): Season and Disease, Proceedings of the Royal Society of Medicine, Epidemiological Section, vol. ii., part 2, p. 1. Peter (1910): Observations upon the Natural History of Epidemic Diarrhoea, Journal of Hygiene, vol. X., p. 602. Purdy (1909) : Flies and Fleas as Factors in the Dissemination of Disease, Journal of the Royal Sanitary Institute, vol. xxx., p. 496. Reed, Vaughan, and Shakespeare (1900): Report on the Origin and Spread of Typhoid in the United States Military Camps during the Spanish War, 1898. Abstract of Report, Washington, Government Printing Office, 1900. Rosenau Lumsden, and Kastle (1.909) : Report No. 3 on the Origin and Prevalence of Typhoid in the District of Columbia, Bulletin No. 52, Hygiene Laboratory, United States Public Health and Marine Hospital Service, Washington, p. 30. Sawtchenko (1892) : Le Rôle des Mouches dans la Propagation de l'Epidemie Cholérique, Vratch (St. Petersburg), review in Annales de l'Institut Pasteur, vol. vii. Simmonds (1892): Fliegen und Cholerauebertragung, Deutsche Medizinische Wochenschrift, p. 931. Smith (1903) : Municipal Sewerage, Journal of Tropical Medicine, vol. Vi. Spillmann and Haushalter (1886): Comptes Rendus de Diarrhoea, Intercolonial Medical Journal of Australasia, March, 1899 Tizzoni and Cattani (1886): Untersuchungen über Cholera, Centralblatt für die Medizinischen Wissenschaften, Berlin, p. 769, 1886. Tooth and Calverley (1901): In a Civilian War Hospital, \&c., in South Africa, Work by the Professional Staff, London, John Murray. Tsuzuki (1904): Bericht ueber meine Epidemischen Beobachtungen, \&c., im Jahre 1902, Archiv fur Schiffs- und Tropenhygiene, Band viii., p. 71. Uffelmann (1892): Beiträge zur Biologie des Cholerabacillus, Berliner Klinische Wochenschrift, ph 1213. Veeder (1898): Flies as Spreaders of Disease in Camps, New Yonk Medical' Record, p. 429 . Weaver, TunniDisease in Camps, New York Medical' Record, p. 429 . Weaver, Tunni-
cliffe, Heinemann, and Michael (1905): Summer Diarrhcea in Infants, cliffe, Heinemann, and Michael (1905): Summer Diarrhcea in Infants,
Journal of Infectious Diseases, vol. ii, p. 70 . Wollstein (1903): The Journal of Infectious Diseases, vol. is, p. 70 . Wollstein (1903) : The
Dysentery Bacillus in a Series of Cases of Infartile Diarrhoea, Journal
of Medical Research, wol. x., p. 11. Yersin (1894) : La Peste Bubonique of Medical Research, rol. X., p. 11. Yersin (1894) : La Peste
à Hongkong, Annales de l'Institut Pasteur, vol. viii., p. 662.

\section{A RECOVERY FROM INFECTIVE ENDOCARDITIS (STREPTOCOCCAL).}

By HENRY HEMSTED, M.D. BRUX., M.R.C.S. EnG., L.R.C.P. LOND.

With Comments by T. J. HORDER, M.D. LoND., F.R.C.P. LOND.

IN this case Mrs. X, a young married woman of 21 , the subject of a congenital lesion of the endocardium, became infected from a tooth abscess on July 6th, 1911. Ulceration of the mural endocardium resulted in innumerable infarcts in the lungs and a few in other tissues. Streptococci were isolated on several occasions from the blood-stream, and the patient, after being ill for nearly a year, has completely recovered in spite of many adventures. She was treated with autogenous vaccines and autogenous serum. In the early stages scattered pulmonary infarcts produced a picture closely simulating acute tuberculous pleuritis.

\section{Detaited Description of Case.}

The patient was known to be the subject of a loud and harsh systolic cardiac bruit, not conducted to the left, of maximum intensity at the right edge of the sternum near the fourth costal cartilage ; and Dr. Aylmer Lewis, of Oswestry, who has known her professionally all her life, gave evidence that the murmur existed from birth. There was slight bulging of the precordial ribs to the left of the sternum, and evidence -clinical and skiagraphic-of hypertrophy of the right ventricle. She had had no previous illnesses, except measles and mumps. There was some reason to infer that her father and paternal uncle may have died from ulcerative endocarditis. Dr. J. H. Drysdale wrote in 1910 that " she has, in my opinion, a congenital lesion of the heart; but not, I believe, pulmonary stenosis." Sir James Goodhart wrote to me on Oct. 6th, 1910 :-

There is, as you know a permanent murmur heard over the lowe 
part of the sternum and for some distance rouml about, which is probably of ventricular origin, but which does unt seem to be hampering the action of the heart much, although $I$ ain told there is palpitation now and then. There is no short breath or alteration of colour, and bealth seems in all respects good. I an therefore of opinion that the patient had better live an ordinary healthy life, and play such games as golf and tennis or ride with moderation. Any excessive tax apon her circulation should, of course, be avoided.

There was every reason to suppose that the bruit was caused by a congenital malformation of the right ventricle similar to that described by Dr. Arthur Keith in THF LANCET of August 7th, 1909. Dr. Keith himself examined Mrs. X on Det. 25th, 1912, and agreed with this diagnosis. In this condition, owing to defective union of the bulbus cordis in the foetus, the ventricle is subdivided into two chambers of varying dimensions. The lower is the true ventricle; the upper is really a dilatation of the infundibulum of the pulmonary artery, and the ostium infundibuli connected the two. The ostium is a muscular foramen with a fibrous margin covered by endothelium which is usually rough and may be covered with vegetations, thus forming an ideal site for the implantation and growth of micrococci. Its size varies greatly, but will often admit one finger or more. Signs and symptoms during life will obviously depend on the calibre of this orifice; the condition is compatible with advanced age and may give rise to no symptoms, being perhaps only discovered at a necropsy. There may possibly be a hereditary predisposition to this cardiac defect, which often co-exists with other malformations of the heart. In the excellent specimens in the Museum of the Royal College of Surgeons prepared by Dr. Keith a perforate ventricular septum is present in 9 out of 19 cases. Specimen 580.5 is an adult heart with a well-marked infundibular chamber in connexion, with the right rentricle, and the ostium and adjacent heart-wall show extensive ulcerative endocarditis which proved fatal.

Mrs. X remained quite well in spite of pregnancy having occurred in April, 1911. In May Dr. Armand Routh saw her and wrote: "There is no evidence of cardiac insufficiency in the local or general condition at this moment. I advise no interference" (with the pregnancy). On July 6th, 1911 , an alveolar abscess had formed in connexion with the first lower left molar, necessitating urgent treatment. After discussing the pros and cons of gas rersus local anesthesia, the latter method was adopted. The gum was infiltrated with novocaine by injection from a dental syringe, the molar removed, and a mouth wash containing euthymol employed. Next day Mrs. X complained of coldness, shivering, pain in the back, and headache; her temperature was $101^{\circ} \mathrm{F}$., and the mouth was inflamed. Feverish symptoms persisted for three or four days, when they subsided and the patient got up and resumed normal habits, in spite of vague symptoms of headache and neuralgic pains at times. She was seen at this time and subsequently by Dr. F. C. Bottomley, and we considered the condition was due to some "septic absorption from the mouth" for which we prescribed antiseptic mouth washes. On August 15th there was pain in the left side resembling pleurodynia, temperature $100^{\circ}$, nothing heard. The pain speedily improved, as also did an attack of "lumbago" on August 20th.

During the next month the patient had occasional pains in the limbs, but a serious view of the case was not suggested intil Sept. 25th, when very severe sciatica on the left side occurred. This was at first thought to be incidental to pregnancy, which was now just over five months advanced. On Sept. 28th Mrs. X took to her bed, and a regular type of intermittent fever developed. The temperature always remained subnormal till mid-day; then a feeling of coldness would come on, accompanied by a rapi. rise of temperature to $101^{\circ}$ or $102^{\circ}$, after which there was profuse sweating. Morning temperature was very low, frequently down to $96^{\circ}$, but the pulse-rate was persistently high, about 120 . She now began to complain of pains in the chest which were accompanied by patches of pleural friction and a little later also by areas of dulness, these being generally, but not exclusively, at one or other base of the lungs. Fresh patches of "pleurisy" occurred every few days, sometimes even daily; one day there would be a rigor and pain in the chest, the next day an increase of dulness would be discovered with adventitious sounds which were either pleuritic or possibly intrapulmonary, and a few days later these signs would have partially cleared if no fresh involvement of that area had occurred. But gradually both bases, and to a less extent the left apex, became persistently dull and remained so for scveral months. The patient now became cyanosed and short of breath, and there was rapid wasting; by the midclle of Oetober her condition had becone very serious.

The clinical picture was one of widespread pleurisy involving the diaphragm. Von Pirquet's test was repeatedly negative; no petechice oceurred. $\Lambda$ lencocytosis of 20,000 per c.mm. was present, but the diagnostic value of this was of course discounted by pregnancy. A few spots of blood were expectorated yielding streptococei, but no sputum coukd be obtained. Cultures from the median basilic veins and blood obtained by puncturing the dull lung yielded nothing at this stage.

Opinion was divided as to whether we wore dealing with an acute disseminated tuberculosis or a multiple infarction of the lungs, Sir James Goolhart, who saw Mrs. X on Oct. 26th, inclining to the latter view. Mrs. $\mathrm{X}$ was seen every day by Dr. Bottomley at this time, and on several occasions by Dr. Hyla Greves. She got rapidly worse-her weight fell from 7 st. on Oct. 13 th to 6 st. $6 \frac{1}{2}$ lb. on Oct. 29 th, and practically the whole of both lungs became involved at one time or another. Rigors occurred nearly every day, pulse very rapid with delirium, constant cough, great dyspncea, and cyanosis. 'There was no sign of disease in any other organs except the lungs.

On Oct. 30th a severe rigor with temperature of $104 \cdot 2^{\circ}$ apparently induced premature labour, and a healthy looking boy of about $6 \frac{1}{2}$ months was born 48 hours later with surprisingly little trouble. (Chart 1.) Oxygen, morphia, and heroin were used freely, and strychnine occasinnally at this time. The placenta showed no sign of tubercle or infarcts, being healthy microscopically and otherwise. After labour and a normal puerperium, a respite in the more urgent symptoms ensued -rigors gradually abated and fever lessened-though wasting continued and the weight on Nov. 18th was 5 st. $11 \mathrm{lb}$.

The clinical picture remained strongly suggestive of acute tuberculosis of the pleura with no sputum. Blood culture was again negative, but whenever any blood was expectorated streptococci were invariably present, though possibly they were due to mouth contamination. During the foregoing five weeks we had given Marmorck's antituberculons serum, polyvalent streptococcus serum, and a streptococcus vaccine made from the expectorated blood, without apparent effect. 'Towards the end of November the disease gradually lighted up again, there being severe "pleurisy" on Nov. 22nd, with temperature $103.6^{\circ}$, and other similar attacks on Dec. 1st, 2nd, and 6th. (Chart 2.)

On Dec. 13th an infarct occurred in the spleen with severe pain for several days, followed by some swelling of that viscus. On Jan. 1st, 1912 , Dr. D. W. Carmalt-Jones secured a sample of blood from the left median basilic vein just before a rigor occurred, and by culture obtained a pure growth of streptococcus conglomeratus in 4 tubes out of 6 , thus clinching the fact that we were dealing with a streptococcic infection of the heart. It at once became obvions that the sudden onsets of pain, fever, and rigors, followed by physical signs of consolidated patches of lung with superjacent plastic pleurisy, were due to washing-off of septic clots from the right side of the heart and infarction thereof in the branches of the pulmonary arteries. During the previous three months there had been some change in the intensity and quality of the cardiac bruit, and the chief feature was a softening and muffling of the murmur, which at times was almost inaudible. 'This phenomenon may have been caused by emphysema which was well marked.

An initial dose of 2 million autogenous raccine prepared by Dr. Carmalt-Jones was injected on Jan. 4th, and this vaccine was repeated in increasing doses and diminishing intervals throughout January, February, March, and April, 1912. In January there was a record period of low temperature three days after the first dose, and a still greater improvement after the third dose given on the 15th, although a fresh pulmonary infarct had occurred on the 10th. (Chart 3.) At this time Mrs. X's weight reached its lowest record of $5 \mathrm{st} .4 \mathrm{lb} .7 \mathrm{oz}$, and she secmed little more than skin and bone. While gradually pushing the vaccine an amelioration of symptoms set in, with improvement in weight, pulse, and fever. The disease assumed a more chronic type and infarcts became less frequent, although on Jan. 30th the liver was probably infarcted.

During February from 3 to 5 million doses of streptococcic 
ChaRt 1.

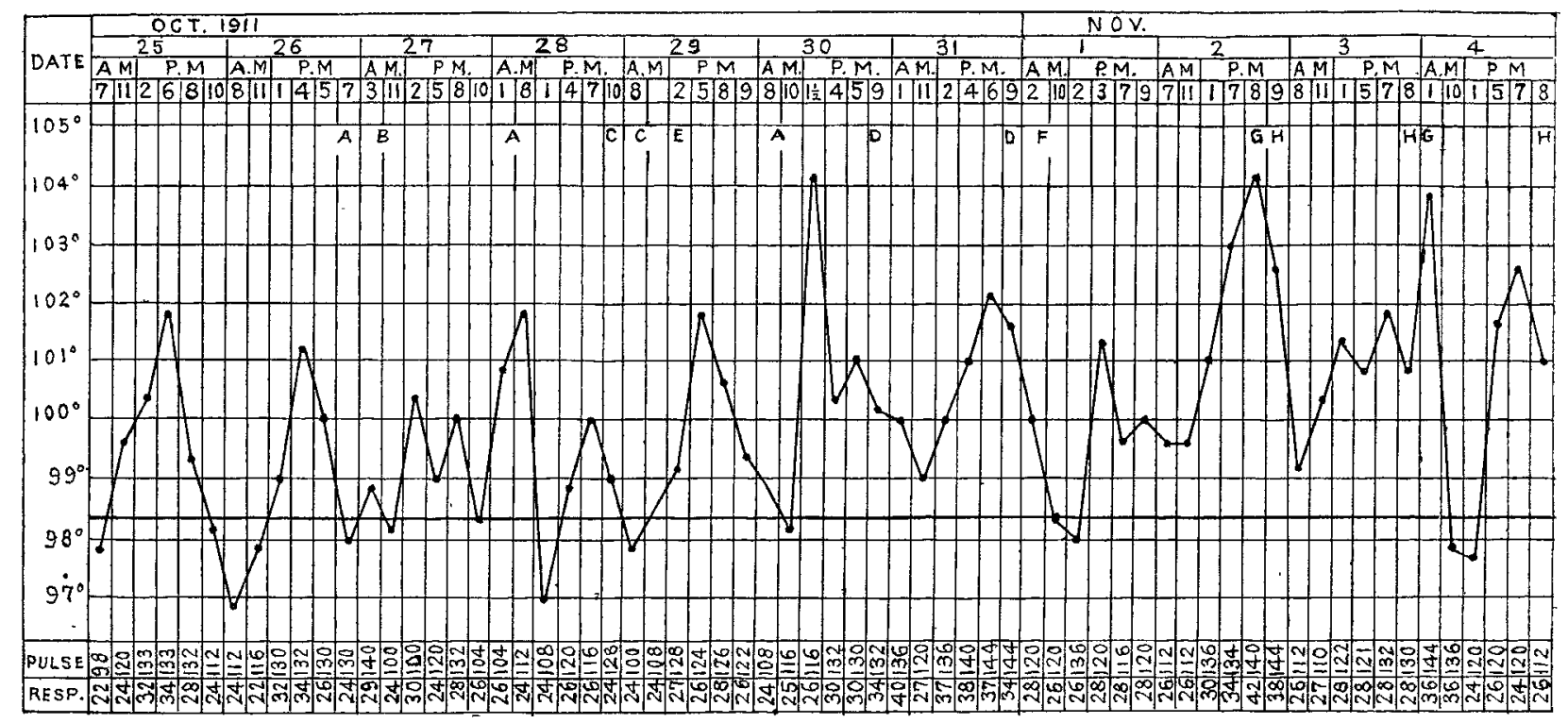

Section of temperature chart during the early stage of the disease, before the occurrence of infarets. At A, rigor and romitiag. $E$, Vomiting. F, Labour (products weighed $4 \frac{1}{4} \mathrm{lb}$.). G, Rigor.

vaccine were given about every third day, and this seemed to be an efficient dose. Temperature averaged $101.5^{\circ}$ each evening and pulse 120 . Weight im proved from 5 st. $8 \frac{1}{2} \mathrm{lb}$. to 5 st. $11 \frac{1}{2}$ lb. On Feb. 22 nd the left lower lung was infarcted.

During March the dose of vaccine was increased and reached 10 millions. The disease now seemed to be dying out, and the temperature rarely reached $101^{\circ}$. There were no rigors, and only two small pulmonary infarcts occurred. Mrs. X was so far recovered that she began to get about, and yet it was certain that the infective process still
Chart 2.

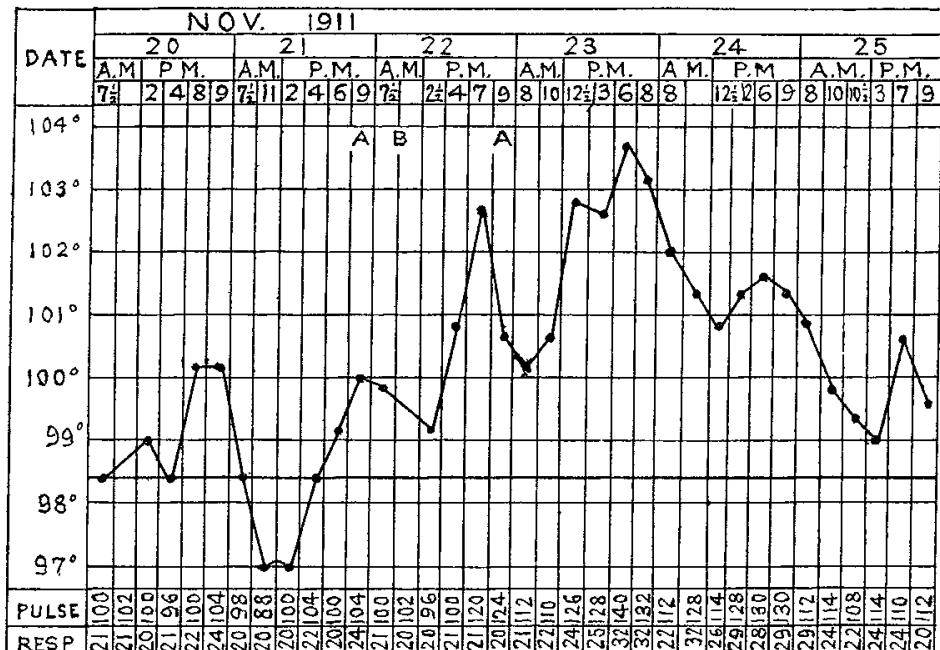

Section of temperature chart showing effect of pulmonary infarction without development of pleurisy. At $\mathrm{B}$ a pulmonary infarct occurred. continued, because a bibood culture by Dr. Horder on March 7th revealed strepto. cocci in all of six broth tubes. Menstruation appeared for the first time during the illness, and remained regular each month ever since. Weight on March 31st, 6 st. $3 \mathrm{lb}$. Blood and a few red corpuscles were found in the urine, followed by a cloud of albumin lasting many weeks, probably caused by a kidney infaret.

During April vaccine was pushed up to 15 millions. and improvement wa maintained till the 12th, when fresh disappointment ensued. A pulmonary infaret occurred on the $^{\text {the }}$

Chart 3.

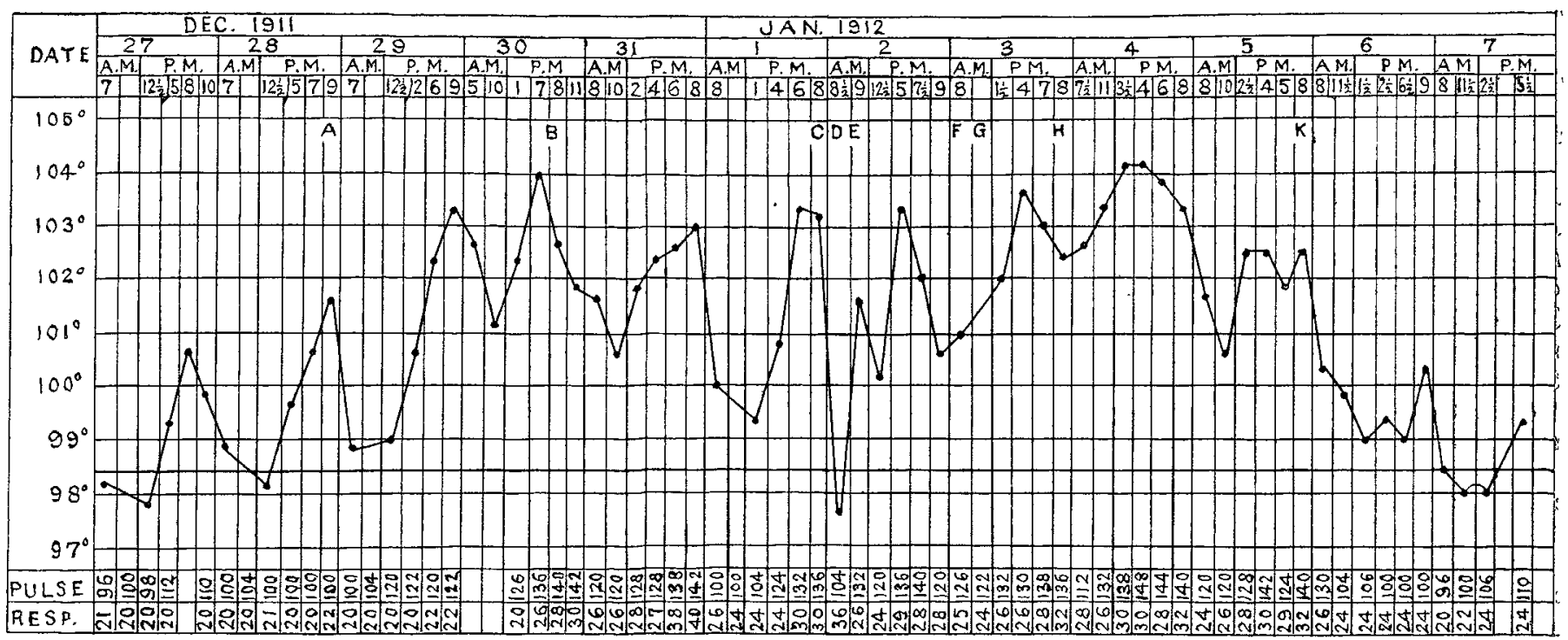
Section of temperature chart showing effect of bilateral pulmonary infaretion with consequent pleurisy. At B, right pulmonary
infarct. F, Rigor. F, Left pulmonary infaret. 
13th, another on the 16th, and a rigor and attack of "sciatica" on the 18th. Fearing a return of all the old symptoms, I seized an opportunity to take Mrs. X to London on the 21st for treatment in a nursing home with autogenous serum which Dr, Horder had advised me to have prepared two months previously.

Arrangements had been made with the director of the Wellcome Physiological Research Laboratories (Dr. H. H. Dale) to have a horse specially injected with increasing doses of the killed culture of Mrs. X's streptococcus. Dr. H. L. Südmersen, who was directly in charge of the immunisation of the horse, kindly supplies the following details :-

A culture of the streptococcus was grown first in glucose broth containing 33 per cent. of fresh horse serum, and afterwards in 2 per cent. glucose broth without serum. A three to four days' growth in the latter medium was killed by heating to $62^{\circ} \mathrm{C}$. and used for hypodermic injection of the horse, a uniform suspension of the organisms being ensured by shaking with sterile glass beads. A fresh culture was prepared for each injection. In order to accelerate the process, a horse was chosen which had already been immunised to a mixture of various streptococci. and, in successive injections at 8 to 10 day intervals, increasing proportions of the special streptococcus were added to the injection mixture until eventually the horse tolerated the $150 \mathrm{c.c}$. of killed pure culture of the special streptococcus. Two bleedings were made- one 10 days after the horse had received 50 c.c. of the special streptococcus with 100 c.c. of mixed streptococcal culture; and the other a month later, 8 days after the final injection of 150 c.c. of special streptococcus culture.

The first dose of 25 c.c. of this special serum was injected into the patient on April 25th and repeated each day for five days. It was suspended on the 27th on account of anaphylaxis. Blood cultures by Dr. Horder on April 25th and again on May 13th generated streptococci on each occasion. But very scanty growth appeared in April, and in May one colony only. After the above series of injections the temperature remained almost normal for nine days till May 12th, when a rigor occurred, followed by another on the 16th, and a small infarction of the right lung. A similar sequence of events on May '25th was associated with plugging of the left lung.

Fresh vaccine, prepared from the latest blood culture by Dr. Horder; was now injected in conjunction with autogenous serum given by the mouth-viz., 25 c.c. of serum were imbibed each morning before breakfast, and 10 millions of the new vaccine given about each fifth day. Some days later a small tender nodule appeared in a finger, and that was the last infarct and the end of all serious symptoms. Serum was continued at increasing intervals till the end of July.

After June 1st Mrs. X picked up weight and strength with marvellous rapidity-lungs quickly cleared, heart and pulse strengthened, temperature remained consistently normal, and weight advanced well over 7 st. The cardiac bruit resumed its original loud character. By September the young lady was able to walk 12 miles, dance, play tennis, sail, bathe, and, in fact, do quite a good day's work without more than perfectly legitimate fatigue. On Sept. 27th she ascended Snowdon (3574 feet) by the mountain railway, and after a climb walked down the mountain. On Oct. 19th she fired three shots (all bulls at 100 yards) from a 0.375 Mannlicher rifle and about 30 from a 12-bore gun without damage to herself or anyone else! Temperature, pulse, and health have remained consistently normal, and $I$ think by now (Dec. 20th) there is no fear of relapse. Perhaps there is even some acquired immunity to reinfection by streptococci.

There are many points of interest in this case :-

1. I believe it is the first case of infective endocarditis where the diagnosis was established up to the hilt which has recovered.

2. Infection probably occurred on July 6th; the disease developed insidiously, and after sundry warnings the patient became really ill on Sept. 25th, an incubation period of 81 days.

3. The grafting of streptococcal infection on top of a congenital or other lesion of the endocardium has been recently insisted on by Dr. Horder and others, and this case seems to emphasise the danoer of allowing micro-organisms a chance to invade the blood-stream where endocarditis exists either in a latent form or by reason of congenital malformations. In this case I believe the heart valves were unaffected, and the ulcerated patch of endothelium was situated in the right ventricle around an ostium guardino an extra or infundibular ventricle leading to the pulmonary artery exactly as in Specimen 580.5 in the Museum of the Royal College of
Surgeons of England above referred to. This condition would account for :-

4. The great predominance of infarcts in the lungs.

5. The invariable presence of streptococci in the expectorated blood.

6. The difficulty in culturing cocci from the systemic veins in the first four months of the disease.

7. I think we may infer that there is no leak in the ventricular septum in this case, by reason of the relative paucity of signs in the systemic circulation.

8. 'The fact of the valves remaining healthy facilitated complete recovery.

Possibly streptococci might have invaded the capillary circulation from the peridental abscess in any erent, but I bitterly regretted sanctioning the infiltration of novocaine into an inflamed gum. It is easy to be wise after the event! 9. Dealing with diagnosis, at first sight, it appears almost ridiculous that for nearly four months we could not exclude tubercular infection of the pleura, but we were faced with the following considerations which complicated the issue : (a) 'The physical signs in right-sided ulcerative heart lesions may, for a time, be limited to the lesser circulatory system, the minute branches of the pulmonary arteries acting as efficient filters for clots, and to a large extent for micrococci. (Obviously a perforate septum would qualify this state of affairs.) It is often impossible to obtain streptococci by blood culture in the early stages, and infarcts rarely suppurate, presumably owing to some attenuation of the organisms after entering the blood-stream. (b) Rigors are extremely rare in tubercular lung disease, except as a result of subsequent infection by cocci. (c) Leucocytosis is uncommon in tubercle, but occurs physiologically when pregnancy exists. (d) In acute phthisis no sputum may be obtainable and von Pirquet's reaction is usually absent. (e) The constant presence of streptococci in blood coughed from the lungs was significant, but not conclusive. Signs of pleurisy with consolidated lung, coupled with fever dyspnoea, rapid wasting, cough, and a curiously optimistic and energetic temperament, are common to both diseases. The latter was a very remarkable feature of Mrs. X's case, and at no time did she realise the gravity of her illness.

Treatment. - As Dr. Horder has kindly consented to append some notes I will only add a few brief remarks.

Morphia and heroin acted like a charm in relieving pain in the chest and the distressing cough. 'The former was advanced up to half a grain, and the heroin hydrochloride up to one-third of a grain, with nothing but beneficial effect. When the disease assumed its more chronic phase the patient attained an extraordinary degree of latitude in feeding and habits. Appetite was often voracious, and her emaciated body was able to sustain far greater exertion than seemed either natural or desirable; before the temperature had become normal walking exercise was attended with benefit, and not with the harm which might have been expected.

Autogenous streptococcus vaccine undoubtedly benefited the temperature and seemed to render the complaint more chronic, but after about three and a half months its virtues seemed to wane. I believe healing of the endocardium and final extermination of the micrococci by destruction of their "factory" were brought about by the autogenous serum prepared, upon Dr. Horder's advice, by Dr. Dale and Dr. Südmersen at the Herne Hill Pathological Laboratory; its action when given by the mouth did not seem to be appreciably diminished, and it was impossible to give it subcutaneously for so long.

I venture to predict that combined treatment with both vaccine and serum derived from the patient's cultured organism will eventually become the standard remedy in this previously hopeless disease.

Dr. Bottomley attended this case with me throughout, and $I$ cannot sufficiently thank him. Sir James Goodhart, Dr. Hyla Greves, Dr. Carmalt-Jones, Dr. Horder, Dr. Dale and others have been unsparing in their skilled help and advice, and my gratitude will be understood when $I$ add that the patient was a near relative of the writer.

\section{Comments by Dr. HORDER.}

In view of the extreme gravity with which all cases of infective endocarditis are quite rightly regarded, Dr. Hemsted's account of this remarkable instance of recovery from the disease is of the utmost importance. 
Dr. Hemsted's theory as to the nature of the congenital heart lesion seems very plausible, and I, think his argument sound. Whether he is right or wrong in this, I am quite convinced that he was dealing with a case of progressive infection of the endocardium by a streptococcus, of the type I shall refer to immediately. The three cardinal signs of " ulcerating or malignant endocarditis" were all present: the evidence of endocarditis was complete, the occurrence of infarcts was undoubted, and micro-organisms were repeatedly isolated from the blood-stream. The history of the diagnostic blood cultures in this case was extremely interesting. Whilst the infection remained localised to the pulmonary circulation, cultures of the systemic blood remained sterile. Later, the general circulation was infected and the streptococci were isolated, at first in large numbers and growing vigorously, but as the patient slowly recovered, in smaller and smaller numbers and growing feebly. In the last culture, made on May 13th, only one colony was isolated after four days' incubation, and this colony could not be recovered from subcultures.

As is so frequently the case when faced with the question, Was the treatment responsible for the cure?-the answer is extremely difficult. The practical point, however, remains : the use of a specifically immunised serum combined with an autogenous vaccine offers the best hope of recovery in infective endocarditis. It is true that few patients can command the enormous expenditure of skill and energy bestowed by Dr. Hemsted on this case, but his very success encourages us to hope for similar results by equally persistent endeavours. When it is remembered that in a considerable number of cases of the disease a positive blood culture is available for the purposes of specific therapy fairly early in its course, it becomes a matter of the utmost importance to proceed along the lines followed in the case here recorded. So far as the serum is concerned, the slower the course of the disease the better the chance of obtaining a high degree of immunity in the horse used for the inoculation. And no doubt the same holds good for the beneficial reaction between the vaccine and the patient's tissues. In the only other reported case where a specially prepared serum was used ${ }^{1}$ no good effects were obtained. But in this case, occurring in the pre-vaccine era, we had not the advantage of combining the active with the passive method of immunisation. During the past few months "sensitised" vaccines have been on trial in the treatment of streptococcal infections, and it may be that the combined use of serum and vaccine in Dr. Hemsted's case acted in a manner similar to these sensitised vaccines.

The characters of the streptococcus obtained from the blood by Dr. Carmalt-Jones and by myself were definitely those of streptococcus salivarius, suggesting, if not actually proving, its origin from the tooth abscess from which the patient suffered. Incidentally, the case provides a warning against the use of local anæsthetics in cases in which periostitis is present. The breaking down of local barriers of defence by the distension of the gum tissue by the injected fluid, together with the opening up of the adjacent lymph spaces, are proceedings evidently to be avoided in such patients. In the presence of old valvular lesions, when it might not unreasonabily be urged that the use of a local anæsthetic would avoid risk to the heart by general anæsthesia, it is clear that if a "septic" tooth is the subject of extraction the lesser evil is the general and not the local anæsthetic.

1 The LANCET, JuJy 16th, 1904, p. 143.

The Cancer Hospital, London.-The medical committee of the Cancer Hospital, Fulham-road, London, S.W., is instituting a course of clinical demonstrations on the diagnosis and treatment of cancer. This course, we understand, has been arranged in response to a widespread demand. In the present state of our knowledge any organised attempt to give regular instruction to the medical profession upon the manifestations and treatment of cancer will assuredly bo welcome. The demonstrations, which will be give 1 on Wednesday afternoons, at 5 P.M., from Jan. 22nd to March 26th, will be free to medical men and senior students.

\section{RUPTURE OF THE SPLEEN AND LIVER; OPERATION ; RECOVERY.}

\author{
By WILlMOTT H. EVANS, F.R.C.S. ENG.,
} SURGEON TO THE ROYAL FREE HOSPITAL.

A BoY, aged 15 years, was run over by a cart on July 2nd last, one wheel passing over the abdomen. About 20 minutes later he was taken to the Royal Free Hospital in a very collapsed condition. He was pale, but not blanched; his respiration was rapid and his pulse was 120 per minute; he complained of pain in the epigastrium. On examination the abdomen was seen to be moving less freely than normally; there was tenderness on palpation, especially in the upper half of the abdomen, and over the same area the muscles were rigid. On the left side of the abdomen was a bruise, suggesting that the wheel had passed over the body from the left side. On percussion the right side of the abdomen was tympanitic, but the left flank and the left iliac fossa were dull, the dulness extending nearer to the middle line at the lower part than elsewhere. The liver dulness was unaltered. A hypodermic injection of strychnine was given and the boy was removed to the ward, where an injection of half a pint of hot saline solution was given by the rectum. His pulse soon fell to 100 beats a minute. $\mathrm{He}$ was very restless and complained of thirst. He vomited two or three times; the first vomit consisted of food tinged with blood, and on the second occasion the vomit contained food only, but it was followed by a few drops of pure blood. A catheter was passed into the bladder, and clear urine was drawn off. I saw him about an hour after the accident, and his condition had changed very little, but the frequency of the pulse had increased, and the dulness was even more marked than before. The general symptoms, the collapse, and the dulness in the left flank after such an injury as the passing of a cart-wheel over the abdomen, suggested that a rupture of the spleen had occurred, and I decided to operate at once.

A vertical incision about three inches long was made over the left rectus near the outer border. The rectus was pushed aside and the posterior layer of the rectus sheath was divided. When the peritoneum was incised a large quantity of blood, estimated at two pints, was found in the peritoneal cavity, and much of this escaped. The spleen was examined and it was found to be torn in several directions nearly completely through, and some of the pieces were almost separated from the main mass. The vessels of the spleen were tied and then divided and the spleen was removed. As much of the blood as could be easily so dealt with was mopped out of the peritoneal cavity, and then a hand was passed into the wound and was carried over to the liver, where two tears were felt. The wound was sewn up in layers with a continunus silk suture. Then a second incision was made on the right side parallel to the margin of the ribs and about three-quarters of an inch from it. It was then seen that there was one tear on the anterior border of the liver and another on the right margin. Each of these was about an inch and a half deep. A third tear was found on the posterior surface of the liver, where the organ is not covered with peritoneum; this tear was deeper than the others.

The patient was very collapsed, and therefore it was thought best to pack the tears in the liver with strips of aseptic gauze. Five strips were used, and the ends were brought out of the middle of the wound, the rest of the incision being sutured. Two pints of hot saline solution were introduced into the median basilic vein, and the boy was returned to bed. It was ordered that half a pint of saline solution should be injected into the rectum every four hours, and that he should have a hypodermic injection of three minims of liquor strychninæ every four hours. By the next morning the patient's colour had improved, his pulse was only 108, and his temperature was $99^{\circ} \mathrm{F}$. He complained of some pain. The saline injections were discontinued, and he was put on milk diet.

On July 5th the gauze packing was removed and the wound was partly closed with stitches; only a small gauze drain was left, and this was removed on the following day. A week after the operation the stitches were removed from the wound on the left side, and from the wound on the right side on July 10th. The wound was completely healed by 